\title{
PEMBUATAN PETA INTERAKTIF KAMPUS ITS SUKOLILO SURABAYA BERBASIS WEB
}

\author{
Ardana Jati Adyatmanto ${ }^{1}$, Muhammad Taufik ${ }^{1}$, Abdul Munif ${ }^{2}$ \\ ${ }^{1}$ Program Studi Teknik Geomatika FTSP-ITS, Kampus ITS Sukolilo, Surabaya, 60111 \\ 2Jurusan Teknik Informatika FTSP-ITS, Kampus ITS Sukolilo, Surabaya, 60111 \\ Email : ardana.adyatmanto@gmailcom,mtaufik@geodesy.its.ac.id, munif@its-sby.edu
}

\begin{abstract}
Abstrak
ITS merupakan salah satu perguruan tinggi negeri dengan wilayah kampusnya yang cukup luas. Minimnya media informasi spasial kampus, seperti peta kampus, yang tidak ditemukan di setiap sudut kampus seringkali membuat seseorang kesulitan mencari tempat tujuannya. Pembuatan suatu peta interaktif mengenai seluruh isi kampus menjadi salah satu solusinya.

Dalam pembuatan peta interaktif tersebut, data spasial yang digunakan adalah peta garis digital Master Plan ITS tahun 2010 dan citra satelit yang diperoleh dari Google Map tahun 2011. Selain gratis, perolehan citra satelit dari aplikasi web tersebut sangat mudah. Namun untuk pemanfaatan citra satelit ini perlu dicatat bahwa pembuatan petapeta yang mengedepankan tingkat ketelitian dengan memanfaatkan citra tersebut tidak direkomendasikan karena tingkat ketelitian geometrik citra satelit dari Google Map terbilang rendah (Hayati, 2011).

Peta interaktif kampus tersebut dapat dimanfaatkan sebagai media informasi spasial kampus dan tidak diperuntukkan untuk keperluan teknis yang membutuhkan tingkat ketelitian geometrik tinggi. Dengan memanfaatkan teknologi HTML5 dan Java Script, peta interaktif kampus tersebut dapat diakses serta diperbarui dengan mudah. Peta tersebut mampu menampilkan berbagai layer dan data non spasial yang lengkap, serta dirancang dengan user-friendly sehingga memungkinkan user mampu mengeksplor seluruh isi kampus secara bebas dengan lebih menyeluruh.
\end{abstract}

Kata Kunci : kampus ITS, peta, interaktif, citra satelit, Google Map

\section{PENDAHULUAN}

\section{Latar Belakang}

Peta adalah gambaran pada lembar kertas keadaan permukaan bumi dengan ukuran yang lebih kecil (Purwohardjo, 1986). Secara umum, fungsi peta dikelompokkan menjadi empat bagian utama yaitu memperlihatkan posisi (baik posisi horizontal maupun posisi vertikal dari suatu objek di permukaan bumi), memperlihatkan ukuran, bentuk serta menghimpun dan menseleksi objekobjek tersebut (Yuwono, 2001). Dengan berbagai fungsi tersebut, peta dapat digunakan oleh masyarakat dengan berbagai latar belakang profesi untuk keperluannya masing-masing.

Seiring dengan perkembangan teknologi informasi dan komunikasi, peta tidak hanya berupa model dua dimensi yang tergambar di atas kertas ataupun dalam format digital, namun juga dituntut agar lebih efektif menyampaikan informasi yang terkandung didalamnya. Hal inilah yang menjadi alasan munculnya peta interaktif, yang memungkinkan para pengguna dapat berinteraksi dengan peta tersebut dan mampu menggali lebih banyak informasi yang terkandung didalamnya.

Kampus ITS Sukolilo Surabaya memiliki wilayah yang cukup luas dengan berbagai bangunan dan sarana pendidikan di dalamnya. Dengan hal ini, tidak jarang menyulitkan bagi seseorang dalam mencari tempat tujuannya. Selain itu, dengan tidak tersedianya peta di tiap sudut kampus membuat seseorang kesulitan karena tidak ada media yang menyajikan informasi mengenai isi kampus.

Saat ini ITS memiliki beragam sistem informasi berbasis web yang saling terintegrasi satu sama lain, seperti Sistem Informasi Akademik, Sistem Informasi Kepegawaian, dan lain-lain. Namun dari sekian banyaknya sistem informasi tersebut, tidak ada satupun yang menyajikan informasi spasial yang berisikan informasi persebaran posisi bangunan di dalam area kampus. Dengan adanya pembuatan peta interaktif kampus ITS yang berbasis $w e b$, diharapkan mampu menyelesaikan 
masalah minimnya infomasi mengenai isi kampus ITS Sukolilo bagi masyarakat.

\section{Rumusan Permasalahan}

Perumusan masalah yang dimunculkan dalam penelitian ini adalah bagaimana cara pembuatan peta interaktif kampus ITS Sukolilo berbasis web yang user-friendly.

\section{Batasan Masalah/Ruang Lingkup}

Batasan permasalahan dari penelitian tugas akhir ini adalah:

1. Daerah penelitian yaitu mencakup kawasan kampus ITS Sukolilo, Surabaya.

2. Data non spasial mengenai :

i. Informasi gedung :

a) Nama gedung

b) Ruangan yang terdapat di dalamnya berdasarkan lantai

c) Foto gedung

ii. Informasi ruangan :

a. Nama ruangan

b. Lokasi lantai

iii. Informasi kantor :

a) Nama kantor

b) Hyperlink website/email kantor

\section{Tujuan}

Tujuan dari penelitian tugas akhir ini adalah pembuatan peta interaktif kampus ITS Sukolilo Surabaya yang dapat diakses via internet dan user-friendly sehingga dapat mengatasi masalah minimnya informasi spasial tentang lingkungan kampus ITS Sukolilo dengan tepat.

\section{Manfaat}

Manfaat dari penelitian tugas akhir ini adalah sebagai berikut:

1. Peta interaktif kampus ITS Sukolilo ini dapat dimanfaatkan oleh seluruh civitas akademika ITS.

2. Kemudahan dalam memperoleh informasi spasial maupun non-spasial terkait lokasi tempat yang ingin dituju dalam kampus ITS.

3. Peta kampus ITS Sukolilo ini dapat juga bermanfaat sebagai media promosi bagi ITS secara umum dan Jurusan Teknik Geomatika ITS secara khusus.

\section{METODOLOGI PENELITIAN}

\section{Lokasi Penelitian}

Lokasi penelitian ini dilakukan di wilayah Kampus ITS Sukolilo yang terletak di wilayah Surabaya bagian Timur dengan posisi geografis pada $07^{\circ} 16^{\prime} 32^{\prime \prime}$ - 07 $17^{\prime} 15^{\prime \prime}$ Lintang Selatan dan $112^{\circ} 47^{\prime} 23,4^{\prime \prime}-112^{\circ} 47^{\prime} 57^{\prime \prime}$ Bujur Timur.

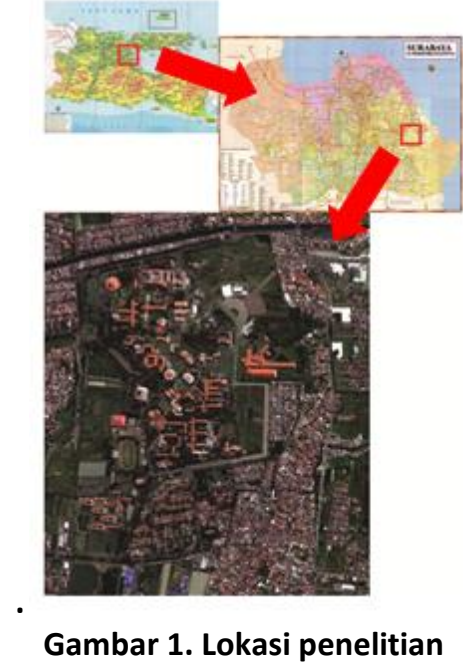

\section{Data Dan Peralatan}

\section{- Data}

Data yang digunakan dalam penelitian ini adalah:

1. Citra satelit kawasan kampus ITS Sukolilo Surabaya dari Google Map tahun 2011 sebagai data spasial.

2. Peta garis digital Master Plan ITS tahun 2010 dari PIMPITS sebagai data spasial.

3. Buku Induk Bangunan Fisik Tahun 2006 dari BAPSI sebagai data non spasial.

4. Model Rencana Pengembangan Jalan Master Plan ITS Tahun 2010 dari PIMPITS sebagai data non spasial.

5. Data gedung, jalan, dan ruangan kampus ITS Sukolilo Surabaya dari survei lapangan sebagai data non spasial.

\section{- Peralatan}

Peralatan yang digunakan dalam penelitian ini adalah:

1. Perangkat Keras (Hardware)
a. Laptop
b. GPS Geodetik Topcon HiPer Pro.
c. Total Station.
d. Roll meter $30 \mathrm{~m}$. 
e. Kamera saku.

2. Perangkat Lunak (Software)
a. Autodesk Land Dekstop 2009
b. Topcon Tools
c. ER Mapper 7
d. Matlab R2008
e. Notepad++ v5.8.5
f. Inkscape 0.48
g. Corel Draw X5

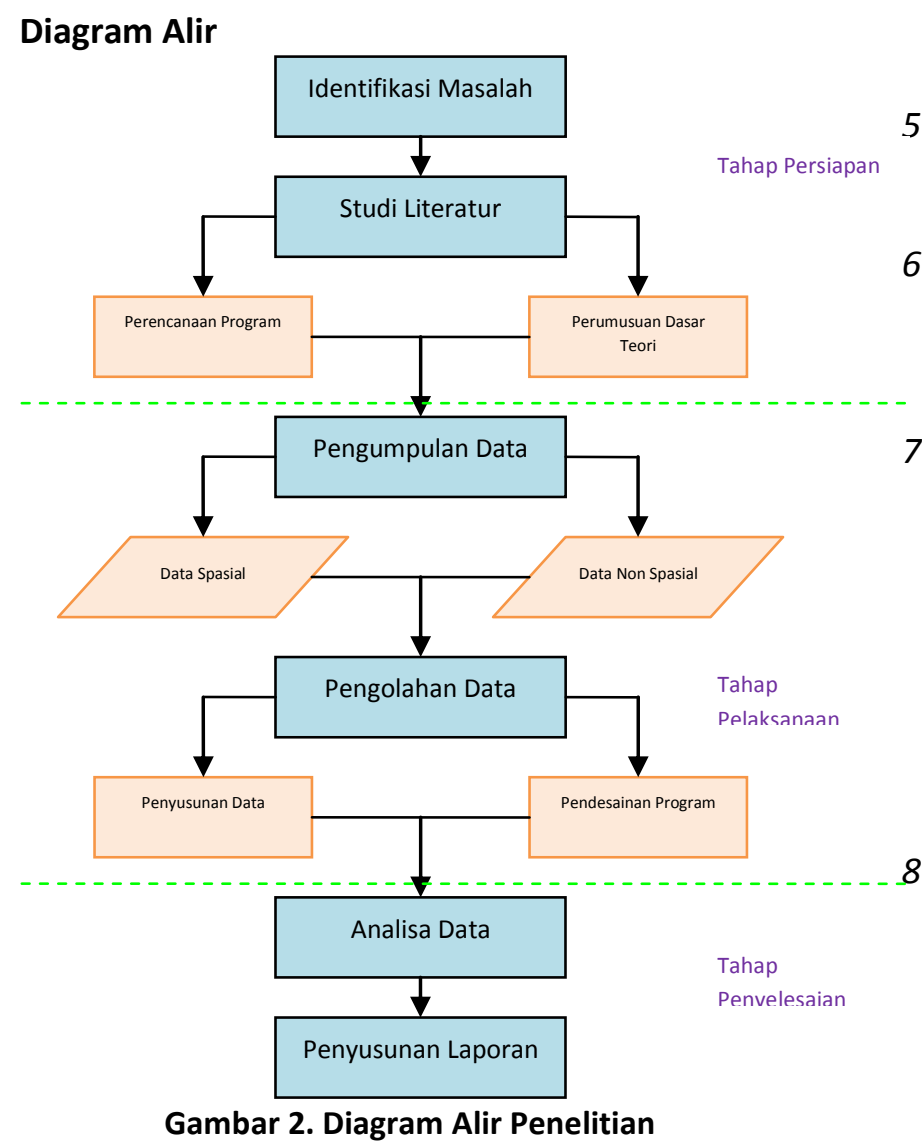

\section{Pengolahan Data}

Dibawah ini adalah penjelasan mengenai diagram alir pembuatan peta Kampus ITS Sukolilo berbasis Web:

1. Data yang digunakan berupa data spasial dan data non spasial. Kedua data tersebut nantinya akan dipadukan.

2. Data spasial berupa citra satelit kampus ITS Sukolilo Surabaya yang diperoleh dari Google Map tahun 2011 dengan menggunakan plug in Screen Grab pada browser Mozilla Firefox, serta peta garis digital Master Plan ITS tahun 2010 yang diperoleh dari PIMPITS.

3. Pertama, perlu dilakukan pengolahan citra secara geometrik dengan menggunakan GPS
Geodetik atas beberapa Ground Control Point (GCP) yang tersebar merata di wilayah kampus ITS Sukolilo dan diolah dengan menggunakan software Topcon Tools. Kemudian baru dilakukan proses pengolahan citra menggunakan software ER Mapper 7 agar citra tersebut memiliki georeferensi.

4. Lalu dilakukanlah proses interpretasi objek atas citra satelit tersebut dengan peta garis digital Master Plan ITS untuk mengetahui bentuk objek yang ada di citra terkait dengan ketidakjelasan citra.

5. Setelah itu citra satelit didigit dengan menggunakan software Autodesk Land Desktop 2009.

6. Untuk selanjutnya dilakukan ground truth untuk pengecekan langsung ke lapangan mengenai kelengkapan bangunan yang ada di lapangan.

7. Apabila bangunan belum lengkap atau belum sesuai secara geometrik, maka perlu pengukuran terrestris terhadap objek atau bangunan yang belum terdapat di dalam kedua data dengan menggunakan Total Station, serta dilakukanlah proses updating dan editing sesuai kondisi lapangan yang sebenarnya. Apabila sudah lengkap maka dilanjutkan ke tahap berikutnya.

8. Setelah itu, maka selanjutnya bisa dilakukan proses interchange format dari format .dwg menjadi format .svg dengan software Inkscape 0.48, dan kemudian di-convert menjadi file .js dengan menggunakan aplikasi web www.readysetraphael.com agar mampu diidentifikasi oleh script HTML5 untuk pembuatan peta interaktifnya.

9. Sedangkan untuk data non spasial berupa data bangunan kampus dari Buku Induk Bangunan Fisik ITS BAPSI Tahun 2006, data nama jalan kampus dari Model Rencana Pengembangan Jalan Master Plan ITS Tahun 2010, serta data atribut dan foto hasil ground truth.

10. Apabila data tersebut tidak sesuai dengan kondisi di lapangan, maka diperlukanlah updating dan editing sesuai kondisi lapangan yang sebenarnya dan dilanjutkan ke tahap penyusunan data akhir. Jika data tersebut sudah sesuai dengan kondisi di lapangan, 
maka bisa dilanjutkan ke tahap penyusunan data akhir.

11. Penyusunan data akhir dilakukan agar data non spasial tersebut tertata dengan baik dan memudahkan saat penggabungan data.

12. Kemudian hasil interchange format peta digital kampus dan data akhir non spasial kampus tersebut digabungkan dalam pembuatan file .js. Pembuatan file tersebut bertujuan agar mempermudah script HTML5, CSS3, dan Javascript dalam bekerja dalam sistem, sekaligus mempermudah proses editing dan updating untuk kedepannya.

13. Setelah itu masuk ke dalam tahap pembuatan script HTML5, CSS3, dan Javascript dengan menggunakan software Notepad++ v5.8.5. Untuk desain grafisnya menggunakan software Corel Draw X5. Dalam tahap ini, file .js yang telah dibuat sebelumnya harus digabungkan dengan script HTML5 dan Javascript agar hasilnya dapat saling berinteraksi. Sedangkan file grafis yang telah dibuat harus digabungkan dengan script CSS3 agar mampu menampilkan wepage layout dengan baik.

14. Jika sudah selesai, maka file-file yang telah disiapkan harus dimasukkan ke dalam server agar mampu diakses secara online. Lalu setting jaringannya agar proses pemanggilan data oleh browser berjalan dengan baik.

15. Kemudian perlu dilakukan uji online. Apabila belum berhasil maka harus melakukan pengecekkan network setting dan script editing, lalu kembali ke tahap pembuatan script HTML5 jika sudah benar. Apabila proses uji online berhasil, maka didapat tampilan akhir berupa Peta Interaktif Kampus ITS Sukolilo Surabaya Berbasis Web.

\section{HASIL DAN PEMBAHASAN}

\section{Hasil Penggambaran Peta Kampus}

Dalam pembuatan peta interaktif kampus ITS Sukolilo, hasil digitasi citra Google Map adalah peta kampus ITS Sukolilo yang memiliki 15 layer, yaitu :

1. Layer Citra

2. Layer Limit

3. Layer Bangunan Klik

4. Layer Bangunan
5. Layer Fasilitas Olahraga

6. Layer Jalan Biasa

7. Layer Jalan Klik

8. Layer Jalan

9. Layer Kampus Lain

10. Layer Koridor

11. Layer Parkir Mobil

12. Layer Parkir Motor

13. Layer Pedestrian

14. Layer Kosong

15. Layer Sungai Danau

\section{Hasil Perancangan Peta Interaktif Kampus}

Sedangkan dalam hasil akhirnya yang berupa peta interaktif kampus ITS Sukolilo, terdapat 13 layer sebagai berikut :

1. Layer Bangunan Klik

2. Layer Bangunan

3. Layer Fasilitas Olahraga

4. Layer Jalan Biasa

5. Layer Jalan Klik

6. Layer Jalan

7. Layer Kampus Lain

8. Layer Koridor

9. Layer Parkir Mobil

10. Layer Parkir Motor

11. Layer Pedestrian

12. Layer Kosong

13. Layer Sungai Danau

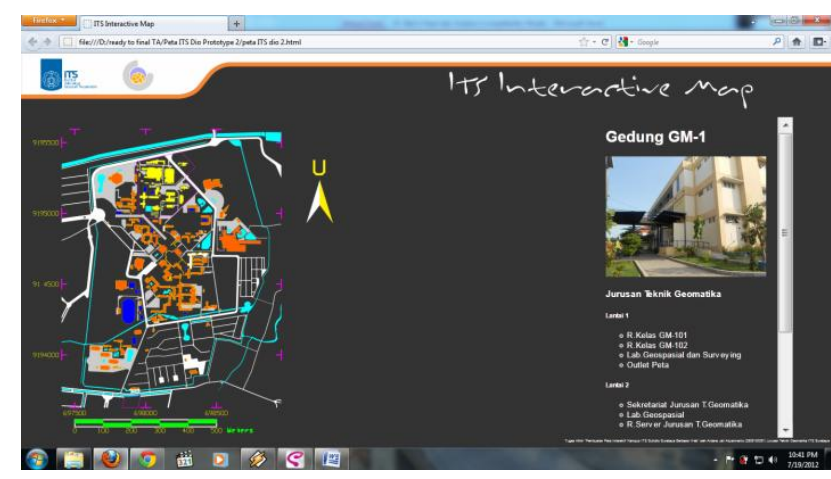

Gambar 4. Tampilan Peta Interaktif Kampus ITS Sukolilo

Untuk data non spasial yang dapat ditampilkan adalah :

1. Informasi gedung :

a. Nama gedung

b. Ruangan yang terdapat di dalamnya berdasarkan lantai

c. Foto gedung 
2. Informasi ruangan:

c. Nama ruangan

d. Lokasi lantai

3. Informasi kantor :

a. Nama kantor

b. Hyperlink website/email kantor

\section{Analisa Data Non Spasial}

Dalam pembuatan peta interaktif kampus ITS Sukolilo ini, peran data non spasial sangat penting. Sumber data diperoleh dari BAPSI dan PIMPITS sebagai sumber data resmi, dan hasil survei lapangan sebagai sumber data faktual.

Dari kedua sumber data tersebut, penggunaan data non spasial cenderung memilih ke data hasil survei lapangan dengan alasan :

1. Arsip data non spasial yang diperoleh dari BAPSI dan PIMPITS tidak update.

2. Peta interaktif kampus ini dirancang untuk menampilkan kondisi lingkungan kampus terkini.

3. Tidak adanya arsip data mengenai toponimi jalan yang ada di dalam kawasan kampus ITS Sukolilo.

4. Ketidaklengkapan data non spasial yang diperoleh dari BAPSI dan PIMPITS.

\section{Analisa Pengukuran GPS Geodetik}

Pada penelitian kali ini Ground Control Point (GCP) yang digunakan sebanyak 8 titik, dimana 7 diantaranya adalah titik yang diukur dengan menggunakan GPS Geodetik Topcon HiPer Pro dan 1 titik adalah GPS CORS ITS yang digunakan sebagai titik yang dianggap benar. Pengukuran GPS tersebut dilakukan dengan metode radial menggunakan dua alat GPS Geodetik Topcon HiPer Pro.

Sebelum melaksanakan pengukuran, perlu adanya perhitungan nilai Strength of Figure (SoF) atas desain jaring pengukuran yang hendak diukur.

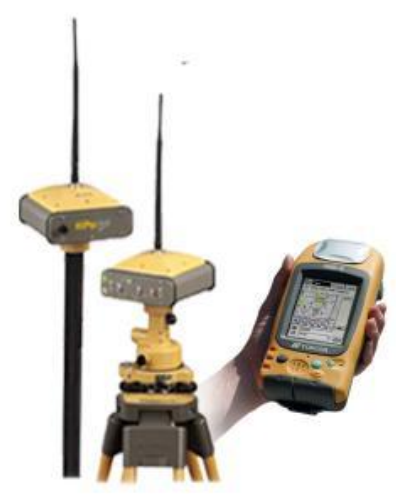

Gambar 5. GPS Geodetik Topcon HiPer Pro

Dikarenakan perhitungan SoF memerlukan persamaan pengamatan yang membutuhkan pengamatan lebih, maka dalam penelitian ini akan membandingkan besar total sudut dalam dengan dua metode yang berbeda, yaitu dengan metode sudut pusat jaring segitiga serta metode sudut dalam jaring segitiga. Konsep pengukuran berdasarkan metode sudut pusat jaring segitiga dijelaskan dalam gambar 6 .

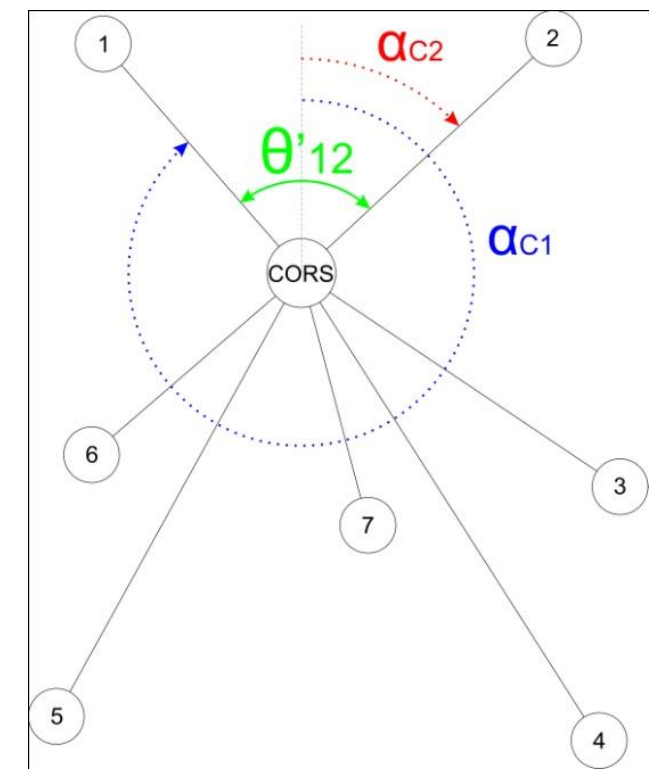

Gambar 6. Metode Sudut Pusat Jaring Segitiga

Dari perhitungan tersebut, didapatkan bentuk persamaan sebagai berikut:

$$
\begin{aligned}
& \theta_{12}^{\prime}=\left(360^{\circ}-\alpha_{C 1}\right)+\alpha_{C 2} \\
& \theta_{23}^{\prime}=\alpha_{C 3}-\alpha_{C 2} \\
& \theta_{34}^{\prime}=\alpha_{C 4}-\alpha_{C 3} \\
& \theta_{47}^{\prime}=\alpha_{C 7}-\alpha_{C 4}
\end{aligned}
$$




$$
\begin{gathered}
\theta_{75}^{\prime}=\alpha_{C 5}-\alpha_{C 7} \\
\theta_{56}^{\prime}=\alpha_{C 6}-\alpha_{C 5} \\
\theta_{61}^{\prime}=\alpha_{C 1}-\alpha_{C 6} \\
360^{\circ}=\theta_{12}^{\prime}+\theta_{23}^{\prime}+\theta_{34}^{\prime}+\theta_{47}^{\prime}+\theta_{75}^{\prime}+\theta_{56}^{\prime}+\theta_{61}^{\prime}
\end{gathered}
$$

Sedangkan untuk konsep pengukuran metode sudut dalam jaring segitiga dijelaskan dalam gambar 7 .

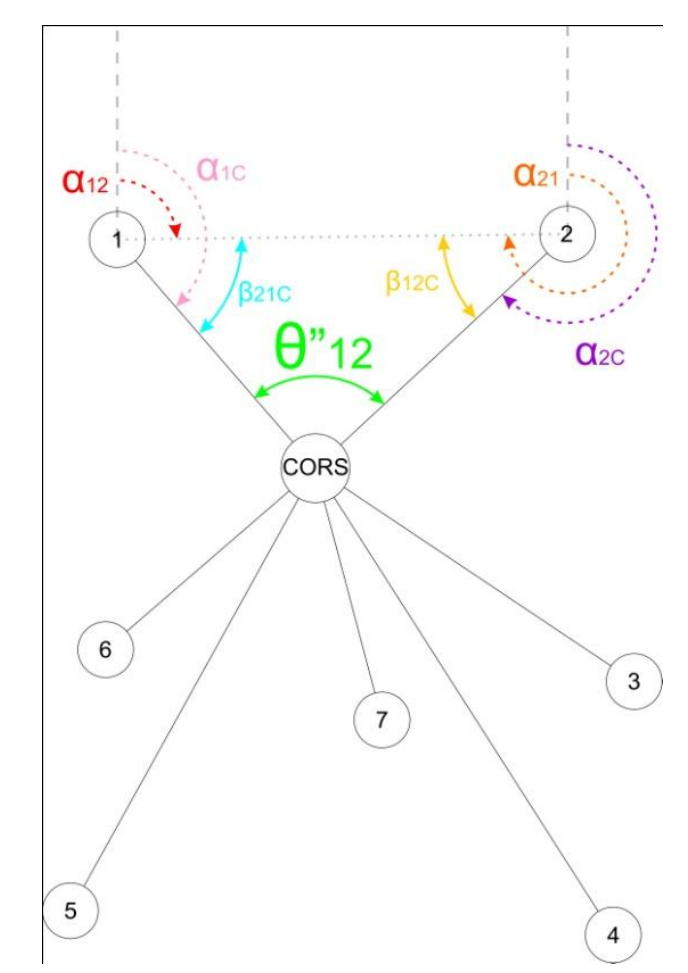

Gambar 7. Metode Sudut Dalam Jaring Segitiga

Dari perhitungan tersebut, didapatkan bentuk persamaan sebagai berikut:

$$
\begin{aligned}
& \theta_{12}^{\prime \prime}=180^{\circ}-\beta_{21 c}-\beta_{12 c} \\
& \theta^{\prime \prime}{ }_{23}=180^{\circ}-\beta_{32 c}-\beta_{23 c} \\
& \theta^{\prime \prime}{ }_{34}=180^{\circ}-\beta_{43 c}-\beta_{34 c} \\
& \theta^{\prime \prime}{ }_{47}=180^{\circ}-\beta_{74 c}-\beta_{47 c} \\
& \theta^{\prime \prime}{ }_{75}=180^{\circ}-\beta_{57 c}-\beta_{75 c} \\
& \theta^{\prime \prime}{ }_{56}=180^{\circ}-\beta_{65 c}-\beta_{56 c} \\
& \theta_{61}=180^{\circ}-\beta_{16 c}-\beta_{61 c}
\end{aligned}
$$

$360^{\circ}=\theta^{\prime \prime}{ }_{12}+\theta^{\prime \prime}{ }_{23}+\theta^{\prime \prime}{ }_{34}+\theta^{\prime \prime}{ }_{47}+\theta^{\prime \prime}{ }_{75}+\theta^{\prime \prime}{ }_{56}+\theta^{\prime \prime}{ }_{61}$

Dari kedua metode tersebut kita dapatkan: Jumlah Titik : 7 Jumlah Pengamatan : 16 Jumlah Parameter : 7 Ukuran Lebih : 9

Dari perhitungan menggunakan Matlab R2008, didapatkan nilai SoF sebesar 0,3403 dimana SoF yang baik memiliki nilai mendekati nol.

Kemudian pengukuran dilakukan dengan menggunakan metode pengamatan rapid static dengan durasi waktu \pm 15 menit. Persebaran lokasi titik pengukuran GCP dapat dilihat pada gambar 8.

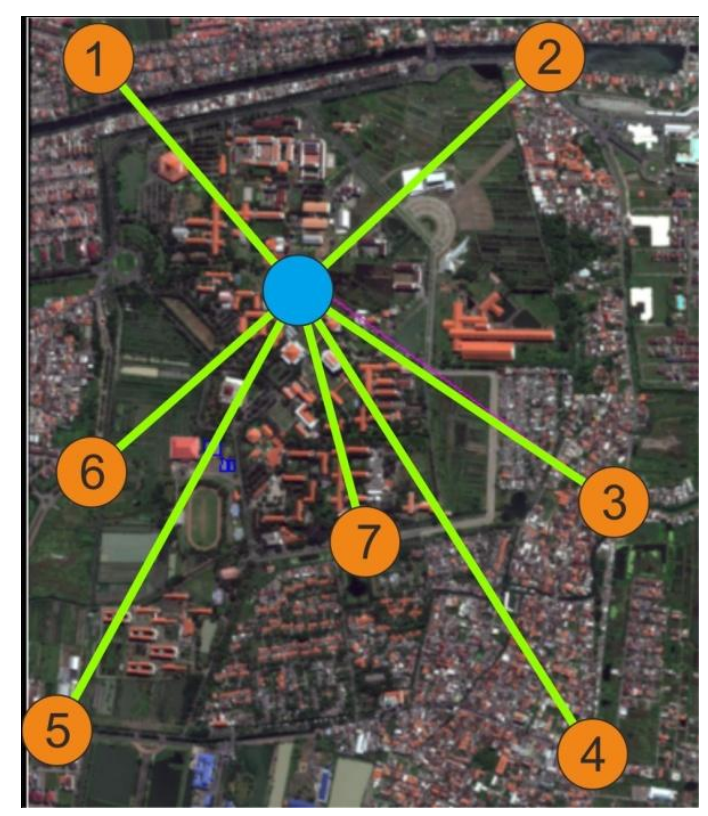

Gambar 8. Lokasi Persebaran Titik GCP 
Dan berikut adalah tabel koordinat GCP hasil pengukuran GPS:

Tabel 1. Koordinat GCP

\begin{tabular}{cccc}
\hline Titik & Northing $(\mathbf{m})$ & Easting $(\mathbf{m})$ & Elevasi $(\mathbf{m})$ \\
\hline 1 & 9195532,811 & 697595,719 & 31,729 \\
2 & 9195538,552 & 698813,744 & 31,658 \\
3 & 9194344,325 & 698983,508 & 31,964 \\
4 & 9193671,737 & 698921,768 & 31,988 \\
5 & 9193743,803 & 697480,869 & 31,784 \\
6 & 9194429,858 & 697576,200 & 32,454 \\
7 & 9194240,316 & 698315,008 & 31,499 \\
ITSS & 9194906,160 & 698128,921 & 47,951 \\
\hline
\end{tabular}

Titik-titik tersebut kemudian digunakan untuk proses rektifikasi citra agar citra tersebut memiliki georeferensi, sehingga dapat dilakukan proses digitasi pada citra tersebut. Sedangkan panjang baseline yang digunakan pada pengukuran tersebut adalah sebagai berikut:

Tabel 2. Panjang Baseline

\begin{tabular}{cc}
\hline Baseline & Panjang Baseline $(\mathrm{m})$ \\
\hline ITSS - 1 & 822,798 \\
ITSS - 2 & 932,149 \\
ITSS - 3 & 1022,730 \\
ITSS - 4 & 1467,108 \\
ITSS - 5 & 1330,806 \\
ITSS - 6 & 729,633 \\
ITSS - 7 & 691,359 \\
\hline
\end{tabular}

Dari tabel tersebut, baseline ITSS - 7 merupakan baseline terpendek dengan jarak 691,359 meter. Sedangkan baseline terpanjang dimiliki oleh baseline ITSS - 4 dengan jarak 1.467,108 meter.

Kemudian untuk mencari besar kesalahan sudut pada pengukuran GPS metode radial, maka antara hasil penjumlahan sudut dalam dengan metode sudut pusat jaring segitiga dan metode sudut dalam jaring segitiga perlu dibandingkan. Berikut adalah tabel perbandingan kedua metode tersebut:

Tabel 3. Perbandingan Besar Kesalahan Sudut Dalam Antara Hasil Perhitungan Metode Sudut Pusat dengan Metode Sudut Dalam Jaring Segitiga

\begin{tabular}{ccr}
\hline Sudut & $\begin{array}{c}\text { Metode Sudut } \\
\text { Pusat }\end{array}$ & Metode Sudut Dalam \\
\hline$\theta_{12}$ & $87,637777^{\circ}$ & $87,637795^{\circ}$ \\
$\theta_{23}$ & $76,084722^{\circ}$ & $76,084703^{\circ}$ \\
$\theta_{34}$ & $23,956111^{\circ}$ & $23,956176^{\circ}$ \\
$\theta_{47}$ & $17,090555^{\circ}$ & $17,090632^{\circ}$ \\
$\theta_{75}$ & $44,737500^{\circ}$ & $44,737456^{\circ}$ \\
$\theta_{56}$ & $20,098055^{\circ}$ & $20,098012^{\circ}$ \\
$\theta_{61}$ & $90,395277^{\circ}$ & $90,395222^{\circ}$ \\
$\boldsymbol{\theta}$ Total & $359,999997^{\circ}$ & $359,999996^{\circ}$ \\
\hline $\boldsymbol{\sigma}$ & $0,000003^{\circ}$ & $0,000004^{\circ}$ \\
\hline Rata-rata & $0,0000035^{\circ}$ & \\
\hline
\end{tabular}

Dari tabel tersebut, dapat disimpulkan bahwa nilai kesalahan yang terkandung pada kedua metode tersebut terbilang sangat kecil, yaitu $0,0000035^{\circ}$, sehingga besar penjumlahan sudut dalam dari pengukuran GPS dengan menggunakan metode radial menghasilkan nilai yang nyaris mendekati $360^{\circ}$.

\section{Analisa Pengolahan Citra}

Citra diperoleh dengan metode screen grab pada browser Mozllla Firefox dan kemudian diolah secara geometrik. Untuk melakukan pengolahan tersebut, diperlukannya GCP yang tersebar secara merata di sekitar wilayah kampus ITS Sukolilo. Dengan menggunakan GPS Geodetik, pengukuran GCP dapat dilakukan. 


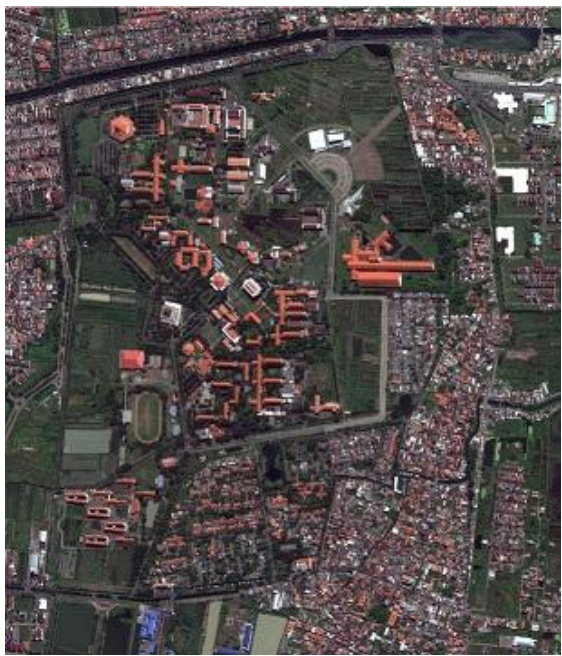

Gambar 9. Citra Satelit dari Google Map Tahun 2011

Setelah didapatkan koordinat dari masing-masing GCP yang tersebar, maka citra tersebut kemudian diolah dan dihitung besar nilai Root Mean Square Error (RMSE). Dengan menggunakan software ER Mapper 7, perhitungan RMSE dapat dilakukan dengan cepat dan mudah. Berikut adalah tampilan tahap perhitungan nilai RMSE pada fasilitas Geocoding Wizard yang disediakan oleh software tersebut.

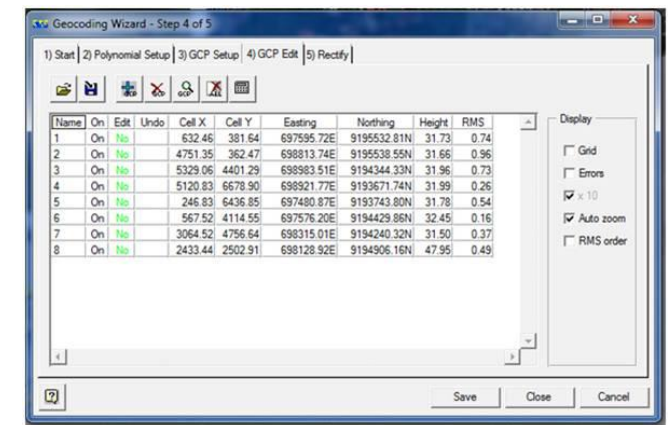

Gambar 10. Proses Geocoding Wizard pada ER Mapper 7

Sedangkan berikut ini adalah tabel hasil perhitungan RMSE dari software ER Mapper 7:
Tabel 4. Nilai RMSE Citra Satelit dari Google Map

\begin{tabular}{cc}
\hline Titik & RMSE (piksel) \\
\hline 1 & 0,74 \\
3 & 0,96 \\
4 & 0,73 \\
5 & 0,26 \\
6 & 0,54 \\
7 & 0,16 \\
8 & 0,37 \\
Total RMSE & 4,25 \\
\hline
\end{tabular}

Dari tabel tersebut didapatkan nilai RMSE ratarata sebesar 0,53 piksel, sehingga nilai RMSE ratarata kurang dari 1 piksel dianggap memenuhi toleransi yang diberikan (Purwadhi, 2001).

\section{Analisa Ketelitian Lapangan}

Untuk mencari tahu seberapa besar ketelitian yang ditampilkan pada hasil digitasi citra satelit Google Map, perlu adanya suatu uji perbandingan antara hasil digitasi citra dengan kondisi nyata di lapangan.

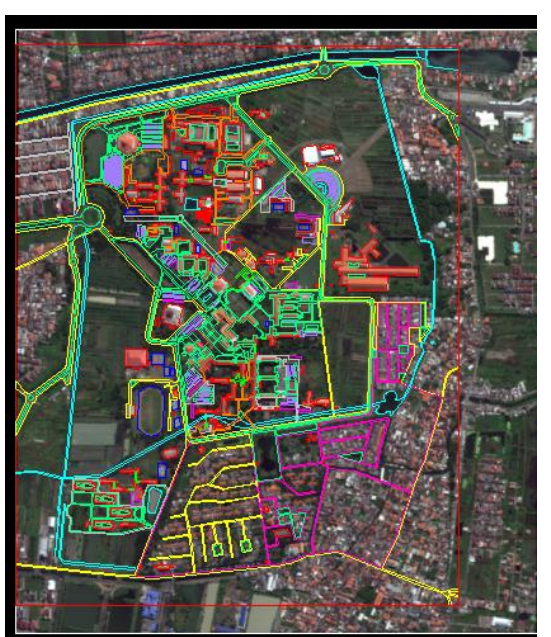

Gambar 9. Hasil Digitasi Citra Kampus ITS Sukolilo 
Analisa tersebut dilakukan dengan membandingkan ukuran lebar jalan pada hasil digitasi citra satelit kawasan kampus ITS Sukolilo dari Google Map tahun 2011 dengan ukuran sebenarnya di lapangan. Pengukuran di lapangan menggunakan roll meter 30 meter dan dengan mengambil 10 sampel jalan yang tersebar di wilayah kampus ITS. Sedangkan pada hasil digitasi, pengukuran lebar jalan dilakukan dengan menggunakan fasilitas pengukuran jarak pada software Autodes Land Desktop 2009. Berikut adalah tabel perbandingan hasil kedua pengukuran tersebut :

Tabel 5. Perbandingan Hasil Ukuran

\begin{tabular}{|c|c|c|c|}
\hline No. & Lokasi & $\begin{array}{l}\text { Digitasi } \\
\text { (m) }\end{array}$ & $\begin{array}{l}\text { Lapangan } \\
\text { (m) }\end{array}$ \\
\hline 1 & Jl.T.Kelautan & 4,861 & 5,333 \\
\hline 2 & Jl.T.Geodesi & 4,837 & 4,673 \\
\hline 3 & $\begin{array}{c}\text { Jl.T.Perkapalan } \\
\text { (Perumdos Blok U) }\end{array}$ & 5,351 & 6,078 \\
\hline 4 & $\begin{array}{c}\text { Jl.T.Kimia } \\
\text { (Pos SKK FTK) }\end{array}$ & 5,353 & 5,676 \\
\hline 5 & $\begin{array}{c}\text { Jl.T.Kimia } \\
\text { (Techno Park) }\end{array}$ & 4,697 & 5,093 \\
\hline 6 & J.Raya ITS & 7,253 & 6,944 \\
\hline 7 & $\begin{array}{c}\text { Jl. Raya Kertajaya } \\
\text { Indah }\end{array}$ & 7,586 & 7,578 \\
\hline 8 & $\begin{array}{c}\text { Jl.Taman Alumni } \\
\text { (Bundaran Manarul - } \\
\text { Arsitek }\end{array}$ & 6,480 & 7,056 \\
\hline 9 & $\begin{array}{l}\text { Jl. Teknik Mesin } \\
\text { (Jurusan Biologi) }\end{array}$ & 5,923 & 5,711 \\
\hline 10 & $\begin{array}{c}\text { Jl. Arief Rahman } \\
\text { Hakim }\end{array}$ & 7,443 & 8,518 \\
\hline
\end{tabular}

Dari data pengukuran hasil digitasi citra satelit Google Map dengan data pengukuran di lapangan didapatkan data hasil selisih antara kedua ukuran tersebut di masing-masing lokasi sebagai berikut:

Tabel 6. Nilai RMSE Ketelitian Lapangan

\begin{tabular}{cc}
\hline No. & $\Delta \mathrm{D}(\mathrm{m})$ \\
\hline 1 & -0.472 \\
3 & 0.164 \\
4 & -0.727 \\
5 & -0.323 \\
6 & -0.396 \\
7 & 0.309 \\
8 & 0.008 \\
9 & -0.576 \\
10 & 0.212 \\
\hline RMSE & -1.075 \\
\hline
\end{tabular}

Dari hasil pengamatan tersebut, diperoleh nilai hasil RMSE pengukuran digitasi citra satelit Google Map terhadap ukuran lapangan. Nilai RMSE digitasi citra satelit Google Map adalah sebesar 0,516 meter.

\section{KESIMPULAN dan SARAN}

\section{Kesimpulan}

Dari hasil pengolahan data dan analisa, kesimpulan yang dapat diambil pada penelitian tersebut adalah :

1. Hasil pembuatan peta interaktif kampus ITS Sukolilo Surabaya mampu menampilkan berbagai layer, data ruangan, serta foto bangunan yang memudahkan user untuk mengetahui informasi tentang kampus ITS Sukolilo dengan lebih mendalam. 
2. Pemanfaatan citra satelit yang diperoleh dari Google Map tidak layak digunakan untuk peta yang mengedepankan ketelitian geometris, namun cukup efektif untuk pembuatan peta tematik dengan proses yang cukup mudah dan murah.

3. Peta interaktif tersebut menggunakan data non spasial hasil survei lapangan sehingga data yang ditampilkan merepresentasikan kondisi kampus terkini.

4. Hasil pengolahan citra secara geometrik memiliki nilai RMSE sebesar 0,53 piksel dan nilai SoF sebesar 0,3403, sehingga hasil digitasi citra tersebut menghasilkan peta dengan sistem koordinat yang baik

5. Nilai kesalahan sudut hasil pengukuran GPS sebesar $0,0000035^{\circ}$, sehingga pemilihan metode radial untuk pengukuran GPS dengan panjang baseline dibawah 1,5 kilometer terbilang efektif dan efisien..

6. Hasil perbandingan pengukuran lebar jalan pada hasil digitasi citra satelit Google Map dengan kondisi lapangan menghasilkan nilai RMSE hasil digitasi terhadap lapangan sebesar 0,516 meter.

\section{Saran}

Dari hasil penelitian tersebut, saran yang dapat diberikan adalah :

1. Peta interaktif kampus ITS Sukolilo tersebut masih perlu dikembangkan agar mampu menjadikannya sebagai media informasi spasial kampus yang lebih baik.

2. Perlu adanya pemanfaatan data citra satelit komersil agar peta yang dihasilkan memiliki tingkat ketelitian yang lebih baik.

3. Untuk pengukuran GPS Geodetik sebaiknya lebih memilih tempat yang memiliki ruang pandang langit yang luas tanpa halangan, lokasi yang lebih mudah diidentifikasi di citra, serta waktu pengamatan yang lebih lama agar hasil pengamatan lebih baik sehingga hasil pengolahan citra menjadi lebih baik.

4. Sebaiknya perlu adanya updating data non spasial dan survei toponimi jalan kampus oleh BAPSI dan PIMPITS agar arsip data yang dimiliki memiliki kualitas yang lebih baik.

\section{DAFTAR PUSTAKA}

Abidin, H.Z. 2007. Penentuan Posisi dengan GPS dan Aplikasinya. Jakarta : PT. Pradnya Paramita.

Arienata, U.P. 2010. Aplikasi Penggunaan Sistem Informasi Geografis Dalam Inventarisasi Ruang Fasilitas dan Gedung Institut Teknologi Sepuluh Nopember (ITS) Surabaya. Surabaya : Program Studi Teknik Geomatika ITS.

Aziz, L. dan Rahman, R. 1979. Pemetaan Tematik. Bandung : Jurusan Teknik Geodesi ITB.

BAPSI ITS. 2011. Institut Teknologi Sepuluh Nopember Profile : Tahun 2010/2011. Surabaya : ITS Press.

Hayati, N. 2011. Kajian Ketelitian Planimetris Citra Resolusi Tinggi Pada Google Earth Untuk Pembuatan Peta Dasar Skala 1:10000 Kecamatan Banjar Timur Kota Banjarmasin. Surabaya : Program Studi Teknik Geomatika ITS.

Khomsin. 2004. Buku Ajar Pemetaan Digital. Surabaya: Program Studi Teknik Geodesi ITS

Kraak, M.J. dan Ormelling, F. 2007. Kartografi : Visualisasi Data Spasial, Yogyakarta : Gadjah Mada University Press.

Potere, D. 2008. "Horizontal Positional Accuracy of Google Earth's High-Resolution Imagery Archieve". Sensors ISSN 1424-8220.

Purwadhi, F.S.H., 2001. Interpretasi Citra Digital. Jakarta :PT.Gramedia Widiasarana.

Purwohardjo, U.U. 1986. Pengukuran Topografi. Bandung : Jurusan Teknik Geodesi ITB.

Sanders, D.H. 1988. Computer Today With Basic, San Francisco : McGraw-Hill

Sarmuji. 2009. Tugas Akhir Pengembangan Sistem Informasi Geografis Untuk Angkutan Kota Surabaya Dengan Sistem Interaktif. Surabaya : Program Studi Teknik Geomatika ITS.

Trainor, T.N. dan Krasnewich, D. 1992. Computers, Watsonville : McGraw-Hill

Villanueva, K.J. 1984. Kartografi. Bnadung : Jurusan Teknik Geodesi ITB.

Williams, B.K. dan Sawyer, S.C. 2007. Using Information Technology : Pengenalan Praktis Dunia Komputer dan Komunikasi, Yogyakarta : Penerbit ANDI

Willy, I.G.N. 2010. Tugas Akhir Pembuatan Peta 3 Dimensi Kampus ITS. Surabaya : Program Studi Teknik Geomatika ITS.

Wongsotjitro, S. 1980. IImu Ukur Tanah, Yogyakarta : Penerbit Kanisius

Yuwono. 2001. Buku Ajar Kartografi Dasar. Surabaya: Program Studi Teknik Geodesi ITS

$<$ URL:http://kartoweb.itc.nl/webcartography/webmap $\mathrm{s} /$ classification.htm $>$. Dikunjungi pada tanggal 8 Februari 2012, pukul 02.37. 
<URL: $\quad$ http://www.viewsoftheworld.net/?p=1820>. Dikunjungi pada tanggal 8 Februari 2012, pukul 03.05.

<URL:http://www.yourhtmlsource.com/starthere/wha tishtml.html>. Dikunjungi pada tanggal 24 Juni 2012, pukul 19.23.

<URL:http://javascript.about.com/od/reference/p/java script.htm>. Dikunjungi pada tanggal 24 Juni 2012, pukul 20.34.

<URL: http://www.roseindia.net/javascript/what-isjavascript.shtml>. Dikunjungi pada tanggal 24 Juni 2012, pukul 21.02.

<URL:http://www.w3.org/standards/webdesign/htmlc ss\#whatcss $>$. Dikunjungi pada tanggal 24 Juni 2012, pukul 21.27
$<U R L:$

http://www.adobe.com/svg/overview/svg.html\#>. Dikunjungi pada tanggal 24 Juni 2012, pukul 21.58. $<U R L$ :

http://www.adobe.com/svg/overview/datadriven. html>. Dikunjungi pada tanggal 24 Juni 2012, pukul 22.10 .

$<U R L$ :

http://www.adobe.com/svg/overview/interactive. html>. Dikunjungi pada tanggal 24 Juni 2012, pukul 22.19.

<URL: http://raphaeljs.com/>. Dikunjungi pada tanggal 24 Juni 2012, pukul 22.31 


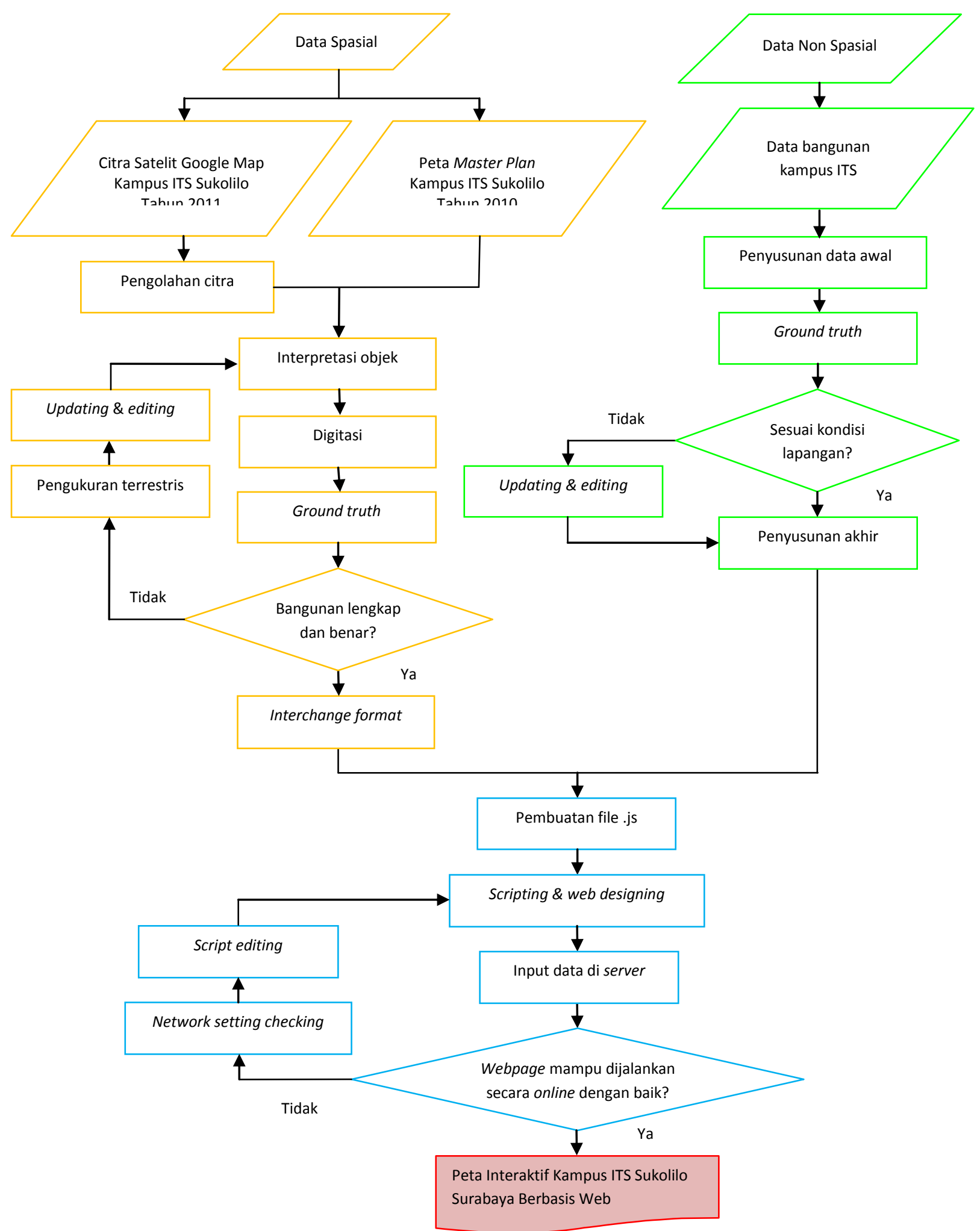

Gambar 2. Diagram Alir Penelitian 